\title{
A review of clinical approaches to antagonism of alpha2- adrenoreceptor agonists in the horse
}

\author{
G. E. Zeiler \\ Department of Companion Animal Clinical Studies, Faculty of Veterinary Science, University of Pretoria, \\ Onderstepoort, South Africa. \\ Corresponding author email: gareth.zeiler@up.ac.za
}

Keywords: horse; $\alpha_{2}$-adrenoreceptor antagonist; atipamezole; tolazoline; yohimbine

\begin{abstract}
Summary
Alpha $_{2}$-adrenoceptor agonists xylazine, romifidine, detomidine and, in some cases, medetomidine and dexmedetomidine, are fundamental drugs used in equine practice. There are situations where the undesirable pharmacodynamic effects (ataxia, prolonged sedation, bradycardia and ileus) or accidental overdose of these drugs may need to be antagonised. The $\alpha_{2}$-adrenoceptor antagonists tolazoline, yohimbine and atipamezole can be used to antagonise undesirable effects. However, despite being effective, $\alpha_{2}$-adrenoceptor antagonists are also not without undesirable pharmacodynamic effects. Excitement, muscle trembling and triggered inappropriate stress responses are a few of the more serious undesirable effects. Horses demonstrate a variable response to the antagonists thus recommending dose rates become fraught with difficulty. It is therefore recommended that the $\alpha_{2}$-adrenoceptor antagonist should be titrated to the desired clinical effect. Consequently, other reversal agents, such as anticholinergics (atropine, glycopyrrolate and hyoscine), have been administered for the treatment of $\alpha_{2}$-adrenoceptor agonist-induced bradycardia. Anticholinergics cannot be recommended for routine use in horses due to the undesirable cardiovascular effects and potentiation of $\alpha_{2}$-adrenoceptor agonist-induced gastrointestinal hypomotility. Novel peripheral acting $\alpha_{2}$-adrenoceptor antagonists, such as MK-467, are currently under scrutiny in veterinary anaesthesia in an effort to antagonise the undesirable effects of $\alpha_{2}$-adrenoceptor agonists without compromising on the level of sedation. This review examines the current literature on the $\alpha_{2}$-adrenoceptor antagonists used in horses and makes recommendations on how to use these drugs safely in an attempt to prevent undesirable pharmacodynamic effects.
\end{abstract}

\section{Introduction}

Alpha $_{2}$-adrenoceptor agonists (xylazine, romifidine, detomidine, medetomidine and dexmedetomidine) are clinically important drugs used in equine veterinary medicine. Xylazine, romifidine and detomidine are licensed for equine use in most countries. However, medetomidine (England and Clarke 1996) and dexmedetomidine (BettschartWolfensberger et al. 2005; Marcilla et al. 2012) have also been administered to horses and ponies despite not being licensed for use. In most cases the package inserts do not provide information on how to antagonise or reverse the pharmacodynamic effects of these drugs in horses and ponies. This review will focus on the $\alpha_{2}$-antagonists (tolazoline, yohimbine and atipamezole) and other drugs that can be considered to reverse undesirable $\alpha_{2}$-agonist effects. An outline of a clinical approach for safe use of these antagonists is also provided.

\section{Clinical use and pharmacodynamic effects of $\alpha_{2}$-adrenoceptor agonists}

The most reliable sedative drugs currently licensed for use in horses are $\alpha_{2}$-agonists. Other beneficial effects of these drugs include analgesia, muscle relaxation, reduction of induction and maintenance anaesthetic drug requirements and attenuation of the stress response to pain and surgery (England and Clarke 1996). Also, $\alpha_{2}$-agonists are used for sedation of horses during transport, as part of preanaesthetic medication for enabling both surgical and nonsurgical standing procedures and as components of analgesic protocols (Vigani and Garcia-Pereira 2014). The beneficial effects of these drugs are mostly due to the interaction with various subtypes of $\alpha_{1}$ and $\alpha_{2}$-adrenoceptors found in the central and peripheral nervous system (Knaus et al. 2007). The $\alpha$-adrenoceptors are distributed at pre- and post synaptic sites within the sympathetic neuro-effector junctions of many organs (Fig 1). Despite the numerous useful qualities of these drugs there are many undesirable clinical effects that may warrant reversal. Bradycardia, ileus and prolonged sedation associated with ataxia are arguably the more common undesirable clinical effects of $\alpha_{2}$-agonists.

Administration of $\alpha_{2}$-agonists results in activation of peripheral receptors $\left(\alpha_{1}\right.$ and $\alpha_{2 B}$ ) on the blood vessels leading to profound vasoconstriction (Knaus et al. 2007). Considering the physiological equation for blood pressure, where blood pressure is equal to cardiac output multiplied by systemic vascular resistance, $\alpha_{2}$-agonist triggered rise in systemic vascular resistance (due to vasoconstriction) causes an increase in blood pressure. Cardiac output is equal to ventricular stroke volume multiplied by heart rate. The physiological mechanism of countering the pronounced increase in blood pressure is to decrease the heart rate via a baroreceptor mediated stimulation of the vagal (cranial nerve $X$; parasympathetic) nerve. This is considered as the initial physiological mechanism for the bradycardia associated with $\alpha_{2}$-agonists. However, once an $\alpha_{2}$-agonist crosses the blood brain barrier, it is thought to suppress the cardiovascular centre through presynaptic inhibition of norepinephrine release. Furthermore, sympathetic tone is also reduced peripherally following the presynaptic inhibition of norepinephrine release (Knaus et al. 2007). Thus the bradycardia can persist due to central effects, despite the waning of the profound peripheral vasoconstriction and hypertension. What is important to consider is the bradycardia-induced decrease in cardiac 


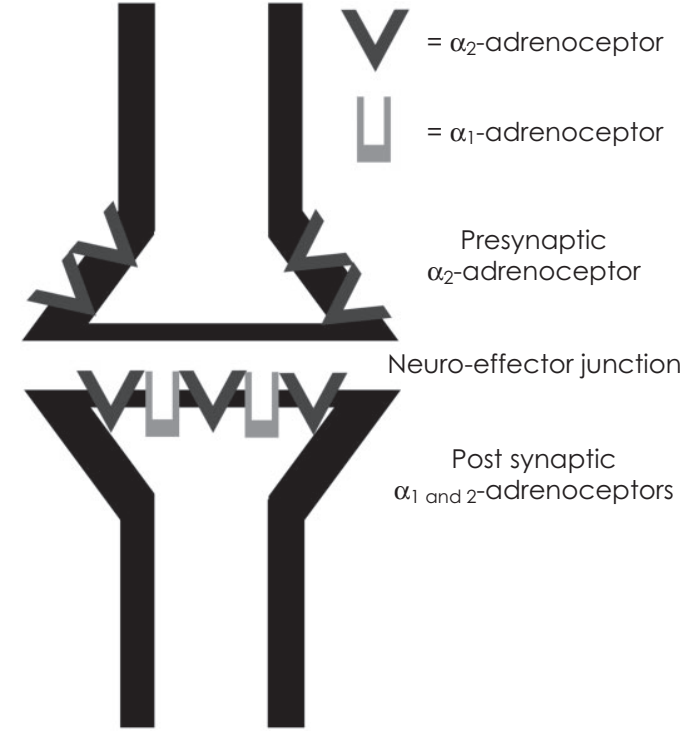

Fig 1: The distribution of pre- and post synaptic $\alpha$-adrenoceptors within the neuroeffector junction of sympathetically innervated organs. Presynaptic $\alpha_{2}$-adrenoceptor activation causes inhibition of norepinephrine and epinephrine release, vasodilation and gastrointestinal hypomotility. Post synaptic $\alpha_{1}$-adrenoceptor activation causes profound vasoconstriction. Post synaptic $\alpha_{2}$-adrenoceptor activation causes sedation, analgesia, anxiolysis, vasoconstriction and inhibition of insulin release.

output of up to $40 \%$ (England and Clarke 1996). Systemic blood pressure is not a reliable indicator of cardiac output thus, despite an often normal or hypertensive systemic blood pressure, there is a decrease in the volume of blood being circulated every minute resulting in less tissue perfusion and oxygenation. The bradycardia may be associated with conduction blocks such as second degree atrioventricular (most common) and sinoatrial blocks (England and Clarke 1996).

Alphan-agonists decrease intestinal motility by peripheral relaxation of the intestine by inhibiting phasic and tonic motor activity, which could perpetuate ileus. This inhibited activity may be associated with stimulation of presynaptic $\alpha_{2}$-adrenoceptors which cause a reduction in acetylcholine release from post ganglionic parasympathetic (vagal nerve terminals) neuro-effector junctions (Roger and Ruckebusch 1987). The visceral analgesic effects of these drugs have been shown to be better than opioid and nonsteroidal anti-inflammatory drugs (Jöchle etal. 1989). As such, $\alpha_{2}$-agonists are excellent analgesics in colic horses, especially those suffering spasmodic intestinal movement disorders. Other mechanisms for decreased motility such as profound vasoconstriction of the lateral caecal artery, which decreases blood supply to this part of the gastrointestinal tract causing local decreased motility, have been described (Rutkowski et al. 1991). The $4 \alpha_{2}$-agonists commonly used in the horse tend to decrease motility in different segments of the gastrointestinal tract, as follows: detomidine tends to decrease gastric emptying (Sutton et al. 2002) and duodenum motility (Merritt etal. 1998) more than xylazine; xylazine decreases jejunum and pelvic flexure motility (Adams et al. 1984) and romifidine decreases small intestinal, caecum and left ventral colon motility (Freeman and England 2001). Medetomidine has not been investigated in horses; however, in the dog it decreases gastric and duodenal motility (Nakamura et al. 1997). The clinical significance of this phenomenon warrants further investigation in horses.

The sedative effects of $\alpha_{2}$-agonists are mediated through interaction with $\alpha_{2}$-adrenoceptors in the locus coeruleus neurons in the pons of the lower brain stem (England and Clarke 1996). The sedative effects are often associated with ataxia. The depth and duration of the sedative effects are both dose and individual horse related. Draught horse breeds are more sensitive to the sedative effects compared to Thoroughbred and Arab horse breeds. Isometric dosing (dosing according to bodyweight) is most likely responsible for the increased perception of sensitivity in draught horse breeds, thus allometric scaling (dosing according to body surface area) should be used to avoid this effect (Sharma and McNeill 2009). Romifidine causes less ataxia compared to the other licensed $\alpha_{2}$-agonists (England etal. 1992). Medetomidine, administered at an equipotent xylazine dose, should be used with caution as it causes more ataxia and may cause the horse to collapse (Bryant et al. 1991). This is especially true if opioids are administered concurrently.

Less clinically significant undesirable effects of $\alpha_{2}$-agonists include hyperglycaemia, diuresis, increased uterine tone, sweating, muscle tremors, hypersalivation, penile protrusion (England and Clarke 1996) and tachypnoea in pyrexic horses (Kendall etal. 2010). These effects are important considerations to bear in mind but may not warrant reversal.

\section{Reversal of undesirable effects of $\alpha_{2}$-adrenoceptor agonists}

The decision to reverse the undesirable effects of $\alpha_{2}$-agonists could be based on an emergency situation, such as a horse collapsing or accidental overdose or on non-emergency clinically relevant situations such as a need to decrease the degree of ataxia. Selection of an appropriate antagonist or reversal drug may prevent undue complications such as excitement or poor cardiovascular performance. Dosages of the $\alpha_{2}$-antagonists described in the text are highlighted in Table 1.

\section{Alpha2-adrenoceptor antagonists}

Tolazoline, yohimbine and atipamezole (both central and peripheral acting $\alpha_{2}$-antagonists) are available in most countries and have been used to antagonise the $\alpha_{2}$-agonists in horses (Knych and Stanley 2014). Only tolazoline has been approved by the Food and Drug Administration (FDA) in the United States of America for reversal of xylazine effects in horses (Casbeer and Knych 2013). Yohimbine is classified as a Class 2 foreign substance by the Association of Racing Commissioners International (ARCI) (DiMaio Knych etal. 2011 ). These pointers are important examples of legal considerations the veterinarian should keep in mind when considering administration of an $\alpha_{2}$-antagonist to a horse. Veterinarians are encouraged to review the legal aspects of drug administration and rules set down by various associations regulating equine related competitions within their country of practice. Despite the highly prevalent off-label use of $\alpha_{2}$-antagonists in horses, there is a growing body of evidence to demystify their clinical effects as observed in horses.

Tolazoline is a synthetic imidazoline derivative that antagonises $\alpha$-adrenoceptors nonselectively (Casbeer and 
TABLE 1: Summary of $\alpha_{2}$-adrenoceptor agonist and antagonist doses used in horses, ponies and donkeys

\begin{tabular}{|c|c|c|c|}
\hline $\begin{array}{l}\alpha_{2} \text {-adrenoceptor } \\
\text { agonist (dose, route) }\end{array}$ & $\begin{array}{l}\alpha_{2} \text {-adrenoceptor antagonist } \\
\text { (dose, route) }\end{array}$ & Reference & Clinical notes \\
\hline- & Tolazoline (4 mg/kg bwt i.v.) & Casbeer and Knych (2013) & $\begin{array}{l}\text { No change in HHAG; decreased HR, increased AV-B, } \\
\text { blood glucose and PCV suggest increased sympathetic } \\
\text { stimulation or attenuation of sympathetic inhibition; } \\
\text { normal faeces passed }\end{array}$ \\
\hline- & $\begin{array}{l}\text { Yohimbine }(0.12 \mathrm{mg} / \mathrm{kg} \text { bwt } \\
\text { i.v.) }\end{array}$ & DiMaio Kynch et al. (201 1a) & $\begin{array}{l}2 \text { of } 8 \text { horses showed signs of sedation; main metabolite } \\
\text { hydroxyl-yohimbine was detected in urine } 96 \mathrm{~h} \text { post } \\
\text { administration suggesting a prolonged withdrawal time } \\
\text { is necessary in competing racehorses }\end{array}$ \\
\hline- & $\begin{array}{l}\text { Yohimbine (0.1, } 0.2 \text { and } \\
0.4 \mathrm{mg} / \mathrm{kg} \text { bwt i.v.) }\end{array}$ & DiMaio Kynch et al. (201 1b) & $\begin{array}{l}\text { Behaviour response consistent in individual horses } \\
\text { regardless of dose administered; however, behaviour } \\
\text { response (either sedation, excitement or unaffected) } \\
\text { was highly variable between horses; muscle } \\
\text { fasciculation at doses } 0.2 \mathrm{mg} / \mathrm{kg} \text { bwt and higher; more } \\
\text { sensitive to environmental stimulation at all doses; HR } \\
\text { increased (tachycardia); PCV and glucose levels } \\
\text { unchanged to baseline; dose-dependent increased } \\
\text { borborygmi }\end{array}$ \\
\hline $\begin{array}{r}\text { Detomidine (0.01 and } \\
0.02 \mathrm{mg} / \mathrm{kg} \text { bwt i.v.) }\end{array}$ & $\begin{array}{l}\text { Atipamezole (6-, 8-, and } \\
\text { 10-fold detomidine dose) }\end{array}$ & Ramseyer et al. (1998) & $\begin{array}{l}\text { Tl: } 15 \mathrm{~min} \text {. Atipamezole administered at } 0.1 \text { or } 0.16 \mathrm{mg} / \mathrm{kg} \\
\text { bwt is adequate to transiently reverse } \\
\text { detomidine-induced moderate and profound sedation, } \\
\text { respectively; ataxia was resolved in all horses }\end{array}$ \\
\hline \multirow[t]{3}{*}{$\begin{array}{l}\text { Detomidine } \\
(0.02 \mathrm{mg} / \mathrm{kg} \mathrm{bwt} \\
\text { i.v.) }\end{array}$} & Tolazoline (4 mg/kg bwt i.v.) & Matthews et al. (1995) & $\begin{array}{l}\text { TI: } 20 \text { min. Tolazoline transiently increased HR in } \\
\text { isoflurane-anaesthetised ponies. A decrease in arterial } \\
\text { partial pressure of oxygen reported }\end{array}$ \\
\hline & $\begin{array}{l}\text { Tolazoline ( } 4 \mathrm{mg} / \mathrm{kg} \text { bwt i.v.); } \\
\text { Atipamezole (0.05 and } \\
0.1 \mathrm{mg} / \mathrm{kg} \text { bwt i.v.) }\end{array}$ & Hubbell and Muir (2006) & $\begin{array}{l}\text { TI: } 25 \text { min. Single bolus of tolazoline or atipamezole } \\
\text { produced partial reversal of detomidine-induced } \\
\text { sedation. Tolazoline, but not atipamezole hastened } \\
\text { recovery }\end{array}$ \\
\hline & $\begin{array}{l}\text { Atipamezole }(0.1 \mathrm{mg} / \mathrm{kg} \text { bwt } \\
\text { i.v.) }\end{array}$ & Raekallio et al. (1990) & $\begin{array}{l}\text { TI: } 15 \text { min. Atipamezole transiently reversed } \\
\text { detomidine-induced bradycardia without overt } \\
\text { undesirable effects }\end{array}$ \\
\hline \multirow[t]{2}{*}{$\begin{array}{l}\text { Detomidine } \\
\text { (0.03 } \mathrm{mg} / \mathrm{kg} \mathrm{bwt} \\
\text { i.v.) }\end{array}$} & $\begin{array}{l}\text { Yohimbine }(0.2 \mathrm{mg} / \mathrm{kg} \text { bwt } \\
\text { i.v.) }\end{array}$ & Knych et al. (2012) & $\begin{array}{l}\text { TI: } 15 \text { min. Detomidine increased yohimbine plasma } \\
\text { concentration, decreased the volume of distribution } \\
\text { and clearance thus affecting withdrawal time }\end{array}$ \\
\hline & $\begin{array}{l}\text { Yohimbine }(0.2 \mathrm{mg} / \mathrm{kg} \text { bw } \\
\text { i.v.) }\end{array}$ & DiMaio Knych et al. (2012) & $\begin{array}{l}\text { TI: } 15 \text { min. Yohimbine was effective in transiently reversing } \\
\text { detomidine-induced sedation, bradycardia, AV-B and } \\
\text { hyperglycaemia }\end{array}$ \\
\hline \multirow[t]{2}{*}{$\begin{array}{l}\text { Detomidine } \\
(0.04 \mathrm{mg} / \mathrm{kg} \mathrm{bwt} \\
\text { i.v.) }\end{array}$} & Tolazoline (4 mg/kg bwt i.v.) & Carroll et al. (1997) & $\begin{array}{l}\text { TI: } 20 \text { min. Tolazoline reversed detomidine-induced } \\
\text { sedation and analgesia in ponies; tolazoline } \\
\text { precipitated a systemic stress response in all ponies } \\
\text { which suggests caution when reversing painful patients; } \\
\text { sweating was noted in all treated ponies }\end{array}$ \\
\hline & $\begin{array}{l}\text { Tolazoline ( } 4 \mathrm{mg} / \mathrm{kg} \text { bwt i.v.); } \\
\text { Atipamezole }(0.4 \mathrm{mg} / \mathrm{kg} \text {, } \\
\text { i.v.) }\end{array}$ & El-Kammar and Gad (2014) & $\begin{array}{l}\text { TI: } 15 \text { min. Tolazoline was more effective than atipamezole } \\
\text { in reversing detomidine-induced sedation, analgesia, } \\
\text { ataxia and bradycardia in donkeys }\end{array}$ \\
\hline $\begin{array}{l}\text { Detomidine } \\
\text { (0.04 mg/kg bwt SL) }\end{array}$ & $\begin{array}{l}\text { Tolazoline (4 mg/kg bwt i.v.); } \\
\text { Yohimbine (0.075 mg/kg } \\
\text { bwt i.v.); Atipamezole } \\
\text { (0.12 mg/kg bwt i.v.) }\end{array}$ & Knych and Stanley (2014) & $\begin{array}{l}\text { TI: } 60 \text { min. Yohimbine, tolazoline and atipamezole } \\
\text { transiently reversed the detomidine-induced sedation } \\
\text { and bradycardia }\end{array}$ \\
\hline $\begin{array}{l}\text { Detomidine } \\
(0.01 \mathrm{mg} / \mathrm{kg} \text { bwt } \\
\text { i.v.) }\end{array}$ & MK-467 (0.25 mg/kg bwt i.v.) & Vainionpää et al. (2013) & $\begin{array}{l}\text { Tl: administered at same time. MK- } 467 \text { prevented } \\
\text { detomidine-induced bradycardia and gastrointestinal } \\
\text { hypomotility without compromising on the level of } \\
\text { sedation }\end{array}$ \\
\hline $\begin{array}{l}\text { Xylazine (bolus } \\
1 \mathrm{mg} / \mathrm{kg} \text { bwt i.v., } \\
\text { followed by } \\
0.72 \mathrm{mg} / \mathrm{kg} \text { bwt/h } \\
\text { CRI) }\end{array}$ & $\begin{array}{l}\text { Average doses required to } \\
\text { reverse sedation: } \\
\text { Yohimbine (0.12 } \mathrm{mg} / \mathrm{kg} \\
\text { bwt i.v.); Tolazoline } \\
(7.5 \mathrm{mg} / \mathrm{kg} \text { bwt) }\end{array}$ & Kollias-Baker et al. (1993) & $\begin{array}{l}\text { TI: } 60 \text { min after start of infusion. Yohimbine and tolazoline } \\
\text { successfully antagonised the xylazine-induced } \\
\text { bradycardia and sedation in horses. Yohimbine } \\
\text { administration demonstrated agitation, muscle tremors } \\
\text { and mild excitement, while tolazoline did not }\end{array}$ \\
\hline $\begin{array}{l}\text { Xylazine (1.0 mg/kg } \\
\text { bwt i.v.) }\end{array}$ & $\begin{array}{l}\text { Atipamezole }(0.15 \mathrm{mg} / \mathrm{kg} \\
\text { bwt i.v.) }\end{array}$ & Luna et al. (1992) & $\begin{array}{l}\text { Tl: } 15 \text { min. Atipamezole shortened the recovery time, } \\
\text { improved respiratory depression and ataxia post } \\
\text { xylazine bolus. No undesirable pharmacodynamics } \\
\text { effects were noted }\end{array}$ \\
\hline $\begin{array}{l}\text { Medetomidine (bolus } \\
0.005 \mathrm{mg} / \mathrm{kg} \text { bwt } \\
\text { i.v., followed by } \\
0.0035 \mathrm{mg} / \mathrm{kg} \\
\text { bwt/h CRI) }\end{array}$ & $\begin{array}{l}\text { Atipamezole }(0.06 \mathrm{mg} / \mathrm{kg} \\
\text { bwt i.v.) }\end{array}$ & $\begin{array}{l}\text { Bettschart-Wolfensberger } \\
\text { et al. (1999) }\end{array}$ & $\begin{array}{l}\text { TI: } 5 \text { min post infusion. Atipamezole promptly reversed } \\
\text { medetomidine-induced sedation without causing } \\
\text { stimulation }\end{array}$ \\
\hline $\begin{array}{l}\text { Medetomidine } \\
(0.01 \mathrm{mg} / \mathrm{kg} \text { bwt } \\
\text { i.v.) }\end{array}$ & $\begin{array}{l}\text { Atipamezole }(0.02,0.04,0.06 \\
0.08 \text { and } 0.1 \mathrm{mg} / \mathrm{kg} \text { bwt } \\
\text { i.v.) }\end{array}$ & Yamashita et al. (1996) & $\begin{array}{l}\text { TI: } 15 \mathrm{~min} \text {. Atipamezole should be bolused at } \\
0.06-0.08 \mathrm{mg} / \mathrm{kg} \text { bwt i.v. to antagonise } \\
\text { medetomidine-induced sedation }\end{array}$ \\
\hline
\end{tabular}

$\mathrm{mg} / \mathrm{kg}=$ milligrams per kilogram; bwt = bwt; i.v. = intravenous; i.m. = intramuscular; SL = sublingual; HHAG = head-height-above-ground measurement; $\mathrm{HR}=$ heart rate; $\mathrm{AV}-\mathrm{B}=$ atrioventricular block; $\mathrm{PCV}=$ packed cell volume; $\mathrm{CRI}=$ constant rate infusion; $\mathrm{Tl}=$ time interval between agonists and antagonist treatment. 
Knych 2013) and possesses histaminergic and cholinergic effects (El-Kammar and Gad 2014). Tolazoline administered i.v. at $4 \mathrm{mg} / \mathrm{kg}$ bwt alone has the following pharmacokinetic profile: systemic clearance, steady state volume of distribution and terminal elimination half-life of $0.82 \pm 0.18 \mathrm{l} / \mathrm{h} / \mathrm{kg}, 1.68 \pm$ $0.38 \mathrm{l} / \mathrm{kg}$ and $2.69 \pm 0.21 \mathrm{~h}$, respectively (Casbeer and Knych 2013). The pharmacodynamic profile when tolazoline is administered alone demonstrates minimal behavioural responses; a decreased heart rate (most likely due to the increased sympathetic tone raising blood pressure and stimulating a baroreceptor mediated increase in vagal tone) with second degree atrioventricular blocks; an increase in blood glucose level and packed cell volume (increased sympathetic tone causing splenic contraction) and unchanged head-height-above-ground (measurement used to determine the level of sedation in horses) compared to baseline readings (Casbeer and Knych 2013). Tolazoline, in isoflurane-anaesthetised (Matthews etal. 1995) or awake sedated ponies (Carroll et al. 1997), is effective in transiently antagonising detomidine-induced bradycardia without inducing arrhythmias or significant alterations to blood pressure. However, Matthews etal. (1995) reported a significant decrease in the arterial partial pressure of oxygen; thus this must be considered when reversing detomidineinduced bradycardia with tolazoline in isofluraneanaesthetised patients. Detomidine-induced sedation (assessed by measuring head-height-above-ground that returns to baseline readings) is effectively antagonised with tolazoline (Carroll etal. 1997). Transient sweating, hypersalivation and gingival hyperaemia may be noticed without overt signs of excitement. Blood glucose, cortisol and free fatty acid levels increase after administering tolazoline which suggests activation of a stress response. This is a clinically significant finding and antagonism of an $\alpha_{2}$-agonist with tolazoline may perpetuate an inappropriate stress response in horses that have undergone a surgical procedure or are in pain for some other reason (Carroll et al. 1997). Stress, in the presence of pain, could culminate in a distressed patient which causes significant metabolic derangements not conducive to convalescence (Gaynor and Muir 2009).

Yohimbine is an indole alkaloid derived from several biological sources (bark of the Pausinystalia yohimbe tree and root of the Rauwolfia serpentina plant) that nonselectively antagonises $\alpha$-adrenoceptors in the horse (DiMaio Knych et al. 2011 a,b). Yohimbine has been shown at high doses to activate other receptor types including $\alpha_{1}$-adrenoceptors, dopamine and serotonin receptors and to inhibit monoamine oxidase (DiMaio Knych etal. $2011 \mathrm{~b}$ ). Yohimbine administered at $0.12 \mathrm{mg} / \mathrm{kg}$ bwt i.v. alone has the following pharmacokinetic profile: systemic clearance, steady state volume of distribution and terminal elimination half-life of $13.6 \pm 2.0 \mathrm{ml} / \mathrm{min} / \mathrm{kg}, 3.2 \pm$ $1.1 \mathrm{l} / \mathrm{kg}$ and $4.4 \pm 0.9 \mathrm{~h}$, respectively, for a 2 compartment model (DiMaio Knych etal. 2011a). Higher i.v. doses of yohimbine $(0.2$ and $0.4 \mathrm{mg} / \mathrm{kg}$ bwt) are associated with an increase in the plasma concentration that decreases in a dose-dependent manner, an increased volume of distribution and slower clearance. The elimination half-life remains consistent (DiMaio Knych et al. 201 1b). Detomidine increases the plasma concentration and decreases the clearance and volume of distribution of yohimbine (Knych et al. 2012). This is clinically significant especially in racehorses where yohimbine is listed as an ARCI Class 2 foreign substance (DiMaio Knych etal. 2011a); veterinarians would need to allow longer withdrawal periods. Pharmacodynamic effects of yohimbine alone are highly variable among horses, regardless of the dose administered (DiMaio Knych etal. 2011b). Sedation or excitation (some horses may demonstrate rearing, striking, running in circles, generalised muscle tremors, agitation and exaggerated but mild excitation in horses exposed to sudden environmental stimulation) are typical pharmacodynamic effects that can be expected and usually resolve within 1-2 $\mathrm{h}$ after yohimbine administration (DiMaio Knych et al. $2011 \mathrm{~b}$ ). Transient cardiovascular and gastrointestinal effects such as an increase in heart rate with disappearance of atrioventricular blocks and an increase in borborygmi, respectively, may be present post yohimbine administration (DiMaio Knych etal. 2011b). Yohimbine antagonism of detomidine has been studied in horses (DiMaio Knych et al. 2012). Yohimbine is effective in antagonising detomidineinduced sedation, bradycardia and atrioventricular blocks. However, the pharmacodynamic response is variable among horses which include transient (approximately $10 \mathrm{~min}$ ) vocalisation, increased arousal and return to normoglycaemia after detomidine-induced hyperglycaemia (DiMaio Knych et al. 2012).

There is no therapeutic indication or justification to use tolazoline (Casbeer and Knych 2013) or yohimbine (DiMaio Knych et al. 2011 b) as a sole agent to treat unsedated horses, due to their unpredictable pharmacodynamic effects.

Atipamezole is a potent, highly selective $\alpha_{2}$-adrenoceptor antagonist (Ramseyer etal. 1998). There is a lack of pharmacokinetic and pharmacodynamics studies based on atipamezole administered alone in horses. Atipamezole antagonism of detomidine-induced sedation (Ramseyer et al. 1998) and bradycardia (Raekallio etal. 1990) have been studied in horses. Atipamezole results in satisfactory but incomplete reversal of detomidine-induced sedation (Raekallio et al. 1990; Ramseyer et al. 1998). However, the level of ataxia is reduced significantly which allows the horse to ambulate properly (Ramseyer etal. 1998). Atipamezole demonstrates a dose dependant increase in undesirable effects such as sweating, hyperexcitability in horses subjected to external stimuli and head shaking that tended to resolve within 10-15 min of injection in detomidine treated horses. Visual signs of arousal are apparent within 2 min of i.v. administration (Ramseyer et al. 1998). Atipamezole transiently antagonises detomidine-induced bradycardia, decreases the frequency of atrioventricular blocks and normalises the arterial blood pressure (Raekallio et al. 1990). Atipamezole effectively antagonises medetomidine constant rate infusion-induced sedation without causing untoward excitement. However, within 2 min of injection, the horse or pony should raise their head, become alert and may even demonstrate signs of shivering and intolerance to surgical drapes or physiological parameter (electrocardiogram leads, noninvasive blood pressure cuffs, etc) monitoring instrumentation (BettschartWolfensberger etal. 1999). Atipamezole also antagonises medetomidine (Yamashita et al. 1996) or xylazine- (Luna et al. 1992) induced sedation after a single i.v. bolus with no apparent undesirable effects.

Two or more $\alpha_{2}$-adrenoceptor antagonists have been compared in a single study to antagonise $\alpha_{2}$-agonists. The antagonistic properties of tolazoline and atipamezole have been compared in detomidine-sedated horses (Hubbell and Muir 2006) and donkeys (El-Kammar and Gad 2014). Both agents produce partial antagonism of detomidine-induced 
sedation and bradycardia. However, tolazoline antagonises detomidine-induced sedation more completely and hastens recovery compared to atipamezole. The clinical effects of tolazoline last longer compared to atipamezole in detomidine treated horses (Hubbell and Muir 2006; El-Kammar and Gad 2014). Apprehension may be anticipated in tolazoline-treated horses while atipamezole does not seem to demonstrate this clinical effect (Hubbell and Muir 2006). Knych and Stanley (2014) have recently reported on the antagonistic effects of tolazoline, yohimbine and atipamezole on sublingually administered detomidine. Yohimbine, but neither tolazoline nor atipamezole, is able to completely return the head-height-above-ground measurements, despite the effect being short-lived (5 min). Yohimbine transiently antagonises detomidine-induced bradycardia to baseline values (predetomidine administration), while tolazoline demonstrates a slight transient increase in heart rate above baseline values. Atipamezole mildly increases the heart rate without returning it to baseline. Tolazoline increased the packed cell volume, unlike yohimbine and atipamezole which had no effect on it. The detomidine-induced hyperglycaemia is antagonised by yohimbine (return to baseline values), worsened by tolazoline (increase in hyperglycaemia) and atipamezole demonstrates no effect on blood glucose level (Knych and Stanley 2014). The antagonistic properties of tolazoline and yohimbine have been compared in xylazine sedated horses (Kollias-Baker et al. 1993). Yohimbine and tolazoline successfully antagonise xylazine-induced bradycardia and sedation. However, yohimbine has a quicker onset and shorter duration of action compared with tolazoline. Yohimbine is also associated with tremors, agitation and excitement, while tolazoline does not demonstrate these behavioural signs in xylazine treated horses. Tolazoline results in a normalisation of the heart rate to baseline readings but is associated with systemic hypertension in the presence of xylazine-induced bradycardia (Kollias-Baker et al. 1993).

A novel peripheral $\alpha_{2}$-adrenoceptor antagonist known as MK-467 (previously L-659'066) has been studied on detomidine sedated horses (Vainionpää et al. 2013). MK-467 prevents detomidine-induced bradycardia and gastrointestinal hypomotility without affecting the quality of sedation. In dogs, MK-467 has been investigated more comprehensively and demonstrates cardiovascular sparing effects without compromising on the level of sedation or general anaesthesia (Honkavaara et al. 2011; Rolfe et al. 2012; Salla et al. 2014). Dexmedetomidine induced alterations in glucose, insulin, free fatty acids and lactate levels are attenuated by MK-467 (Restitutti et al. 2012).

\section{Other pharmacological drug interventions}

The $\alpha_{2}$-agonist-induced bradycardia and intestinal hypomotility can be partially or completely reversed using drugs other than the $\alpha_{2}$-antagonists. In the past, bradycardia was reversed with traditional anticholinergic drugs (atropine and glycopyrrolate). However, these drugs decrease gastrointestinal motility even further which may contribute to ileus and are thus not recommended for routine use (Pimenta et al. 201 1; Perotta et al. 2014). Their use may still be valuable in emergency reversal of profound bradycardia (<24 beats/min) in association with hypotension (mean arterial pressure $<60-65 \mathrm{mmHg}$ ). Hyoscine-N-butylbromide (hyoscine), a nontraditional anticholinergic alkaloid agent derived from Hyoscyamus niger (Henbane), has been used as a successful alternative to atropine to reverse detomidine-induced (Pimenta et al. 2011) and medetomidine-induced (Perotta etal. 2014) bradycardia in sedated horses. The detomidine-induced gastrointestinal hypomotility is not perpetuated by hyoscine, unlike atropine. Hyoscine has a shorter duration of action when compared to atropine in horses. However, pronounced tachycardia, systemic hypertension, increased myocardial workload and oxygen demand negate the routine use of hyoscine in combination with detomidine or medetomidine (Pimenta et al. 2011; Perotta et al. 2014). The intramuscular route of administration is preferred for the anticholinergics to minimise the unwanted cardiovascular effects (Perotta et al. 2014).

Gastrointestinal hypomotility and post operative ileus are clinical concerns in equine practice (Zullian et al. 2011). The odds of developing post operative ileus following xylazine treatment are not significantly different from those not receiving xylazine (Cohen et al. 2004). Despite tolazoline and yohimbine being used as prokinetics in patients suffering from ileus (Cohen et al. 2004; Zullian et al. 2011), the veterinarian must consider that pain can contribute to ileus (Cohen et al. $2004)$ and that $\alpha_{2}$-agonists are excellent visceral analgesics (Jöchle etal. 1989). Thus lidocaine may suffice as an alternative drug to consider, despite its mechanism of action not being fully understood. Treating horses with lidocaine for post operative ileus or enteritis results in shorter hospital stays (Malone et al. 2006). Lidocaine may be infused in combination with $\alpha_{2}$-agonists. Other prokinetic agents such as erythromycin, metoclopramide, tegaserod and bethanechol could also be considered in the treatment of ileus.

\section{Clinical approach to reversal of undesirable $\alpha_{2}$-adrenoceptor agonist effects}

The review has covered the current literature and understanding of $\alpha_{2}$-antagonists that can be used in horses to reverse undesirable pharmacodynamic effects of $\alpha_{2}$-agonists. However, a few considerations need to be highlighted:

1) The dose time interval from administering the $\alpha_{2}$-agonist to cause sedation until the horse receives the antagonist is somewhat consistent (approximately $20 \mathrm{~min}$ ) in academic studies. This may not reflect true clinical practice. The $\alpha_{2}$-antagonist should be dosed according to the expected plasma concentration of the $\alpha_{2}$-agonists. The depth and duration of the sedative effects is dose dependent. The higher the dose, the deeper and longer the sedation. However, after a single bolus, the plasma concentration will gradually decrease over time due to redistribution, metabolism and elimination of the drug. Thus, if the veterinarian still considers it necessary to antagonise the clinical effects of the $\alpha_{2}$-agonist, then the longer the interval between administering the agonist and antagonist the lower the initial antagonist dose should be to prevent unwanted effects (such as excitement). An acceptable approach is to administer a quarter to a third of the recommended i.v. dose initially (Table 1), followed by the same aliquot dose 5-10 min later until an acceptable clinical response is achieved.

2) The dose titration, as described in (1), may be of added benefit due to the variable and unpredictable response between horses to the $\alpha_{2}$-antagonists. Horses tend to demonstrate more obvious variability in response to 
yohimbine, in comparison to atipamezole and tolazoline, in that order.

3) Tolazoline appears to activate a systemic stress response which should be taken into consideration if antagonising a painful $\alpha_{2}$-agonist sedated horse.

4) Yohimbine appears to cause more pronounced transient excitement in comparison to atipamezole and tolazoline, in that order.

5) Atipamezole is the shortest acting and tends to completely or partially antagonise medetomidine- or detomidineinduced sedation, respectively. It is considered a good choice to antagonise $\alpha_{2}$-agonist-induced bradycardia.

6) The end point of $\alpha_{2}$-agonist-induced sedation antagonism should be when the horse can move freely without ataxia. This is because the complete antagonism (return of head-height-above-ground measurement) tends to be transient for all $\alpha_{2}$-antagonists.

7) The analgesic properties of the $\alpha_{2}$-agonists may be antagonised and should be a consideration in patients that are painful or who have undergone a surgical procedure. Nonsteroidal anti-inflammatory and/or opioid drugs should be included in the analgesic management protocol of these patients. However, the $\alpha_{2}$-antagonists may also antagonise opioid based analgesia that is dependent upon spinal adrenergic pathways (Morales et al. 2001).

8) Anticholinergic drugs should only be reserved for emergency reversal of $\alpha_{2}$-agonist-induced bradycardia in the presence of hypotension. Hyoscine, compared to atropine or glycopyrrolate, may be more appropriate as it does not potentiate $\alpha_{2}$-agonist-induced gastrointestinal hypomotility.

A case report by Di Concetto et al. (2007) highlights the importance of titration of an $\alpha_{2}$-antagonist to clinical effect. They described atipamezole reversal of a detomidine (300 $\mu \mathrm{g} / \mathrm{kg}$ bwt in total) overdose in a pony. The atipamezole dose was titrated until the desired clinical effect (pony standing) and they did not notice any undesirable clinical effects of atipamezole. The total dose administered was 3.9 times greater than the detomidine total dose (Di Concetto et al. 2007). The recommended dose in horses is 5-10 times the detomidine dose (Raekallio et al. 1990; Ramseyer et al. 1998), which in this case would have been unnecessary.

\section{Conclusion}

This review examined the current literature regarding $\alpha_{2}$-adrenoceptor antagonists tolazoline, yohimbine and atipamezole in horses. Horses appear to be sensitive to the undesirable pharmacodynamic effects of the antagonists and demonstrate excitement, sweating, muscle trembling and inappropriate stress response, to name but a few. Current antagonist dose recommendations tend to be larger than clinically necessary. Horses tend to demonstrate variable responses to the different antagonists. Thus, these agents should ideally be titrated to clinical effect to avoid the undesirable effects. A peripheral acting $\alpha_{2}$-adrenoceptor antagonist, MK-467, has demonstrated promising results in antagonising undesirable $\alpha_{2}$-adrenoceptor agonist-induced bradycardia and ileus while unaffecting the quality of sedation. It is evident from the review that further clinically-orientated research is warranted to improve our understanding of $\alpha_{2}$-adrenoceptor antagonism in horses.

\section{Author's declaration of interests}

No conflicts of interest have been declared.

\section{Acknowledgements}

The author would like to express thanks and appreciation to the reviewers for their guidance and assistance in improving this review article.

\section{References}

Adams, S.B., Lamar, C.H. and Masty, J. (1984) Motility of the distal portion of the jejunum and pelvic flexure in ponies: effects of six drugs. Am. J. Vet. Res. 45, 795-799.

Bettschart-Wolfensberger, R., Bettschart, R.W., Vainio, O., Marlin, D. and Clarke, K.W. (1999) Cardiopulmonary effects of a two hour medetomidine infusion and its antagonism by atipamezole in horses and ponies. Vet. Anaesth. Analg. 26, 8-12.

Bettschart-Wolfensberger, R., Freeman, S.L., Bowen, I.M., Aliabadi, F.S., Weller, R., Huhtinen, M. and Clarke, K.W. (2005) Cardiopulmonary effects and pharmacokinetics of i.v. dexmedetomidine in ponies. Equine Vet. J. 37, 60-64.

Bryant, C.E., England, G.C.W. and Clarke, K.W. (1991) Comparison of the sedative effects of medetomidine and xylazine in horses. Vet. Rec. $129,421-423$.

Carroll, G.L., Matthews, N.S., Hartsfield, S.M., Slater, M.R., Champney, T.H. and Erickson, S.W. (1997) The effect of detomidine and its antagonism with tolazoline on stress-related hormones, metabolites, physiologic responses, and behavior in awake ponies. Vet. Surg. 26 , 69-77.

Casbeer, H.C. and Knych, H.K. (2013) Pharmacokinetics and pharmacodynamic effects of tolazoline following intravenous administration to horses. Vet. J. 196, 504-509.

Cohen, N.D., Lester, G.D., Sanchez, L.C., Merritt, A.M. and Roussel, A.J. (2004) Evaluation of risk factors associated with development of postoperative ileus in horses. J. Am. Vet. Med. Ass. 225, 1070-1078.

Di Concetto, S., Archer, M.R., Sigurdsson, S.F. and Clarke, K.W. (2007) Atipamezole in the management of detomidine overdose in a pony. Vet. Anaesth. Analg. 34, 67-69.

DiMaio Knych, H.K., Covarrubias, V. and Steffey, E.P. (2012) Effect of yohimbine on detomidine induced changes in behavior, cardiac and blood parameters in the horse. Vet. Anaesth. Analg. 39, 574-583.

DiMaio Knych, H.K., Steffey, E.P., Devel, J.L., Shepard, R.A. and Stanley, S.D. (2011 a) Pharmacokinetics of yohimbine following intravenous administration to horses. J. Vet. Pharmacol. Ther. 34, 58-63.

DiMaio Knych, H.K., Steffey, E.P. and Stanley, S.D. (2011b) Pharmacokinetics and pharmacodynamics of three intravenous doses of yohimbine in the horse. J. Vet. Pharmacol. Ther. 34, 359-366.

El-Kammar, M.H. and Gad, S.B. (2014) Antagonism of detomidine-induced sedation, analgesia, clinicophysiological and haematobiochemical effects in donkeys using intravenous tolazoline or atipamezole. J. Equine Vet. Sci. 34, 784-792.

England, G.C.W. and Clarke, K.W. (1996) Alpha2 adrenoceptor agonists in the horse - a review. Br. Vet. J. 152, 641-657.

England, G.C.W., Clarke, K.W. and Goossens, L. (1992) A comparison of the sedative effects of three alpha2-adrenoceptor agonists (romifidine, detomidine and xylazine) in the horse. J. Vet. Pharmacol. Ther. 15, 194-201.

Freeman, S.L. and England, G.C. (2001) Effect of romifidine on gastrointestinal motility, assessed by transrectal ultrasonography. Equine Vet. J. 33, 570-576.

Gaynor, J.S. and Muir, W.W. (2009) Handbook of Veterinary Pain Management, 2nd edn., Mosby Elsevier, Missouri, USA.

Honkavaara, J.M., Restitutti, F., Raekallio, M.R., Kuusela, E.K. and Vainio, O.M. (2011) The effects of increasing doses of MK-467, a peripheral alpha 2 adrenergic receptor antagonist, on the cardiopulmonary effects of intravenous dexmedetomidine in conscious dogs. J. Vet. Pharmacol. Ther. 34, 332-337.

Hubbell, J.A.E. and Muir, W.W. (2006) Antagonism of detomidine sedation in the horse using intravenous tolazoline or atipamezole. Equine Vet. J. 38, 238-241. 
Jöchle, W., Moore, J.N., Brown, J., Baker, G.J., Lowe, J.E., Fubini, S., Reeves, M.J., Watkins, J.P. and White, N.A. (1989) Comparison of detomidine, butorphanol, flunixin meglumine and xylazine in clinica cases of equine colic. Equine Vet. J. 7, 111-116.

Kendall, A., Mosley, C. and Bröjer, J. (2010) Tachypnea and antipyresis in febrile horses after sedation with alpha 2 agonists. J. Vet. Intern. Med. 24, 1008-1011.

Knaus, A.E., Muthig, V., Schickinger, S., Moura, E., Beetz, N., Gilsbach, R. and Hein, L. (2007) Alpha2-adrenoceptor subtypes - unexpected functions for receptors and ligands derived from gene-targeted mouse models. Neurochem. Int. 51, 277-281.

Knych, H.K. and Stanley, S.D. (2014) Effects of three antagonists on selected pharmacodynamic effects of sublingually administered detomidine in the horse. Vet. Anaesth. Analg. 41, 36-47.

Knych, H.K., Steffey, E.P. and Stanley, S.D. (2012) The effects of yohimbine on the pharmacokinetic parameters of detomidine in the horse. Vet. Anaesth. Analg. 39, 221-229.

Kollias-Baker, C.A., Court, M.H. and Williams, L.L. (1993) Influence of yohimbine and tolazoline on the cardiovascular, respiratory, and sedative effects of xylazine in the horse. J. Vet. Pharmacol. Ther. 16 350-358.

Luna, S.P., Beale, N.J. and Taylor, P.M. (1992) Effects of atipamezole on xylazine sedation in ponies. Vet. Rec. 130, 268-271.

Malone, E., Ensink, J., Turner, T., Wilson, J., Andrews, F., Keegan, K. and Lumsden, J. (2006) Intravenous continuous infusion of lidocaine for treatment of equine ileus. Vet. Surg. 35, 60-66.

Marcilla, M.G., Schauvliege, S., Segaert, S., Duchateau, L. and Gasthuys, F. (2012) Influence of a constant rate infusion of dexmedetomidine on cardiopulmonary function and recovery quality in Isoflurane anaesthetized horses. Vet. Anaesth. Analg. 39 49-58.

Matthews, N., Erickson, S., Light, G., Slater, M. and Hartsfield, S. (1995) Antagonism of detomidine with tolazoline in isoflurane-anaesthetised ponies. Vet. Anaesth. Analg. 22, 25-30.

Merritt, A.M., Burrow, J.A. and Hartless, C.S. (1998) Effect of xylazine, detomidine, and a combination of xylazine and butorphanol on equine duodenal motility. Am. J. Vet. Res. 59, 619-623.

Morales, L., Perez-Garcia, C. and Alguacil, L.F. (2001) Effects of yohimbine on the antinociceptive and place conditioning effects of opioid agonists in rodents. Br. J. Pharmacol. 133, 172-178.

Nakamura, K., Hara, S. and Tomizawa, N. (1997) The effects of Medetomidine and xylazine on gastrointestinal motility and gastrin release in the dog. J. Vet. Parmacol. Ther. 20, 290-295.

Perotta, J.H., Canola, P.A., Lopes, M.C., Évora, P.M., Martinez, P.E.B. Escobar, A. and Valadão, C.A.A. (2014) Hyoscine-N-butylbromide premedication on cardiovascular variables of horses sedated with medetomidine. Vet. Anaesth. Analg. 41, 357-364.

Pimenta, E.L.M., Teixeira Neto, F.J., Sá, P.A., Pignaton, W. and Garofalo, N.A. (2011) Comparative study between atropine and
hyoscine-N-butylbromide for reversal of detomidine induced bradycardia in horses. Equine Vet. J. 43, 332-340.

Raekallio, M., Vainio, O. and Karjalainen, J. (1990) The influence of atipamezole on the cardiovascular effects of detomidine in horses. Vet. Anaesth. Analg. 17, 50-53.

Ramseyer, B., Schmucker, N., Schatzmann, U., Busato, A. and Moens, Y. (1998) Antagonism of detomidine sedation with atipamezole in horses. Vet. Anaesth. Analg. 25, 47-51.

Restitutti, F., Raekallio, M., Vainionpää, M., Kuusela, E. and Vainio, O. (2012) Plasma glucose, insulin, free fatty acids, lactate and cortisol concentrations on dexmedetomiodine sedated dogs with or without MK-467: a peripheral alpha 2 adrenoceptor antagonist. Vet. J. 193, 481-485.

Roger, T. and Ruckebusch, Y. (1987) Colonic alpha 2-adrenoceptormediated responses in the pony. J. Vet. Pharmacol. Ther. 10 310-318.

Rolfe, N.G., Kerr, C.L. and McDonell, W.N. (2012) Cardiopulmonary and sedative effects of the peripheral alpha 2 adrenoceptor antagonist MK-0467 administered intravenously or intramuscularly concurrently with medetomidine in dogs. Am. J. Vet. Res. 73, 587-594.

Rutkowski, J.A., Eades, S.C. and Moore, J.N. (1991) Effects of xylazine butorphanol on cecal arterial blood flow, cecal mechanical activity, and systemic hemodynamics in horses. Am. J. Vet. Res. 52, 1153-1158.

Salla, K., Bennett, R.C., Restitutti, F., Junnila, J., Raekallio, M. and Vainio, O. (2014) A comparison in dogs of medetomidine, with or without MK-467, and the combination acepromazine-butorphanol as premedication prior to anaesthesia induced with propofol and maintained with isoflurane. Vet. Anaesth. Analg. 41, 163-173.

Sharma, V. and MCNeill, J.H. (2009) To scale or not to scale: the principles of dose extrapolation. Br. J. Pharmacol. 157, 907-921.

Sutton, D.G., Preston, T., Christley, R.M., Cohen, N.D., Love, S. and Roussel, A.J. (2002) The effects of xylazine, detomidine, acepromazine and butorphanol on equine solid phase gastric emptying rate. Equine Vet. J. 34, 486-492.

Vainionpää, M.H., Raekallio, M.R., Pakkanen, S.A.E., Ranta-Panula, V., Rinne, V.M., Scheinin, M. and Vainio, O.M. (2013) Plasma drug concentrations and clinical effects of a peripheral alpha-2-adrenoceptor antagonist, MK-467, in horses sedated with detomidine. Vet. Anaesth. Analg. 40, 257-264.

Vigani, A. and Garcia-Pereira, F.L. (2014) Anesthesia and analgesia for standing equine surgery. Vet. Clin. N. Am.: Equine Pract. 30, 1-17.

Yamashita, K., Yonezawa, K., Izumisawa, Y. and Kotani, T. (1996) Antagonistic effects of atipamezole on Medetomidine-induced sedation in horses. J. Vet. Med. Sci. 58, 1049-1052.

Zullian, C., Menozzi, A., Pozzoli, C., Poli, E. and Bertini, S. (2011) Effects of alpha2-adrenergic drugs on small intestinal motility in the horse: an in vitro study. Vet. J. 187, 342-346. 